\title{
ANATOMICAL INVESTIGATION ON THE AXIAL SKELETON OF THE CATTLE EGRET, BUBULCUS IBIS.
}

\author{
H.M. REZK \\ Department of Anatomy and Embryology, Fac. Vet. Med., Cairo Univ. \\ Email: hamdyrezk81@cu.edu.eg
}

Assiut University Email: www.aun.edu.eg

Key words: Cattle egret, skeleton, anatomy, skull, bone cleaning.

\section{INTRODUCTION}

The Cattle Egret (Bubulcus ibis) is a cosmopolitan species of heron (family Ardeidae) found in the tropics, subtropics and warm temperate zones. It is the only member of the monotypic genus Bubulcus. Cattle egret is popular for its role in the bio-control of cattle parasites and land pests, it feeds on a wide range of prey, particularly insects and moths as well as spiders, frogs, earth-worms and fishes and is locally distributed in Nile Delta and Valley Abou Shafey (2012).

The importance of cattle egret to the farmer has initiated an increasing interest to establish more accurate and specific anatomical facts about the skeleton of cattle egret.

The available anatomical literatures concerning this subject are extensively reviewed, but the cattle egret skeleton is rather scanty. Therefore, it appeared that it received the least interest. The present study was conducted to investigate in details the specific structures of the skeleton of the cattle egret.

\section{MATERIALS and METHODS}

The present study was conducted on five adult, apparently healthy, cattle egrets. The birds were euthanized, and then eviscerated, skinned and muscles were removed from skeleton. The eyes extirpated away from the sclerotic ring. The tongue removed from the hyoid and the brain removed from the skull (Sullivan and Romney, 1999).
The skull was disarticulated from the neck, the wings and hind limbs were disarticulated from the body, leaving the thoracic cage and vertebral column in one piece. The skull and the body were soaked in a strong solution of ammonia (90\%) for 7 days. The specimens were checked every 2 days then rinsed and brushed carefully with toothbrush to remove the remaining flesh. The previous step was repeated every 2 days with scraping and trimming any tendons. The specimens were rinsed in dilute Clorox ${ }^{\circledR}$ to remove the odor of ammonia (Tahon et al., 2013).

The nomenclature used in this study was that given by the Nomina Anatomica Avium by Baumel et al. (1993).

\section{RESULTS}

\section{The skull}

Cranium: The skull of the cattle egret has a posterior part (neurocranium) for lodging the brain and an anterior part (splanchnocranium) comprising mainly the bones of the face. The two parts are clearly separated by the very large orbital cavities.

The neurocranium consists of the occipital, sphenoid, parietal, frontal and temporal bones.

Os occipitalis: The occipital bone constitutes the most caudal part of the skull. It is composed of four bones completely fused together and enclosing a large passage; the foramen magnum (fig.1/30), through which the spinal cord and its meninges come out. 
These bones are, the supraoccipitalis (fig.1/32), basioccipitalis (fig.1/33) and paired exoccipitalis (fig.1/31).

The supraoccipital bone bears the transverse nuchal crest (Crista nuchalis transversa) or (crista occipitalis) (fig.1\&2/21). The latter crest extends caudolaterally reaching the paroccipital process (Ala posttympanica) (fig.3/15) and separating the occipital bone from the parietal and temporal bones.

The basioccipital bone forms mainly the single occipital condyle (fig. $1 \& 4 / 28$ ) which articulates with the condyloid fossa of the atlas forming the atlantooccipital joint.

Os parietalis: The parietal bones (fig.1, 2 \&3/17) are thin bony plates which are situated between the supraoccipital and frontal bones.

Os frontale: The frontal bones are well developed in cattle egret. Each one is differentiated into three parts; the frontal parts (fig.1, $2 \& 3 / 16$ ) ambulated and form part of the roof of the cranium. They articulate caudally with the parietal bones. A shallow longitudinal frontal depression (fig.2/20) is situated between the right and left parts. The orbital parts of the frontal bones (fig.2/18) are flat plates extending laterally to form the supraorbital margin (fig.2/19) while the nasal parts (fig. $2 \& 3 / 3$ ) make the major part of the roof of the nasal cavity.

Os temporalis: The temporal bone consists of two parts; the Os oticum (ear capsule) and squamous part (Os squamosum). The latter part bears the wide external acoustic meatus. The squamous part of the temporal bone bears a short orbital process (fig.3/11) and a small zygomatic process (fig.3/34) caudal to the former one.

The Splanchnocranium comprises the bones of the face; ethmoid bone, nasal bones, premaxillary bones, maxillary bones, jugal bones, palatine bones, pterygoid bones, vomer bone, and quadrate bone.

Os ethmoidale: The ethmoid bone consists of two parts; Os mesethmoidale and Os ectethmoidale. The former bone (fig.3/10) forms much of the rostral osseous part of the interorbital septum. While the latter bone is a vertical bony plate forming the rostral part of the orbit, separating the orbit from the nasal cavity rostrally.

Os nasale: The nasal bones are thin flat bones forming the dorsolateral boundary of the nasal cavity and form part of the upper beak. Each nasal bone has two processes; frontal process connects the nasal bone to the frontal bone (fig. $2 \& 3 / 5$ ) and the maxillary process (fig. $3 / 4$ ) is directed ventrolaterally to connect the maxillary bone.
Os premaxillare (Incisive bones) or (Intermaxillary bones): The premaxillary bones (fig. $2,3 \& 4 / 1)$ are paired bones which are fused together forming a pointed, apical region of the upper jaw called rostrum maxillae. The premaxillary bone has three processes on either side; frontal, maxillary and palatine processes. Each process connects the premaxilla to the corresponding bone.

Os maxillare: The maxillary bones (fig.2, $3 \& 4 / 2$ ) are small paired bones forming the caudolateral part of the upper beak; each bone has a palatine process (fig.4/23) which directed ventrally to the palatine bone forming part of the bony hard palate.

Os jugale: The jugal bones (Zygomatic bones) are thin rod-like bone. They connect the upper jaw with the quadrate bone caudally and consist of three fused bones; jugal processes of maxillary bone (fig. $3 \& 4 / 6$ ), the proper jugal bones (fig. $3 \& 4 / 7$ ), and the quadratojugal bones (fig. $3 \& 4 / 8$ ). The latter connected caudally to the quadrate bone.

Os palatinum: The palatine bones (fig.4/24) are narrow and long flat bones that extended parallel to each other. They form the bony roof of the pharynx and there is a slit-like opening between them forming the single posterior nares (Choana) (fig.4/26).

Os pterygoidium: The pterygoid bones (fig.4/27) are short, strong, flat bones which articulate rostrally to the palatine and caudally with the quadrate bones.

Vomer: The vomer bone (fig.4/25) is a single median, laterally compressed plate. It articulates caudally with the palatine bone.

Os quadratum: The quadrate bones (fig. $3 \& 4 / 12$ ) are quadrilateral in shape which lies between the neurocranium and pterygoid bone. The quadrate bone has three processes; otic, orbital and mandibular processes. The otic process (fig.3/14) forms a movable joint with the squamous temporal bone caudally, the orbital process (fig.3/13) points toward the orbit, While the mandibular process (articular process) articulates ventrally with the mandible, articulates laterally with the quadratojugal bone, and articulates medially to the pterygoid bone.

Ossa sclera (scleral ossicles): The sclerotic ring (fig. $1_{\mathrm{b}}$ ) is a series of overlapping thin bony plates, thirteen in number, forming a ring in the sclera of the eye.

Os lacrimale: The lacrimal bones (prefrontal bones) (fig.2\&3/9) thin flat bones are located in the rostral margins of the orbits. It articulates with the lateral rami of the nasal bone and to a lesser extent to the frontal bone. 
Mandibula: The mandible (the lower jaw) (fig.5\&6) is V-shaped, consisting of right and left diverging mandibular rami which are fused rostrally forming the mandibular symphysis (rostrum mandibulae) (fig.5\&6/1). The mandible is formed of seven bones fused with each other in the adult and their sutures are obscured by ossification which are; $O S$ mentomandibulare (fig.5\&6/2), Os dentale (fig.5\&6/3), Os spleniale (fig.5\&6/4), Os supraangulare (fig.5\&6/5), Os prearticulare (fig.5\&6/6), $O s$ articulare (fig.5\&6/7) and $O s$ angular (fig.5\&6/8). The Os supra-angulare (supra angular bone) has the coronoid process (fig.5\&6/11) on its dorsal border and the mandibular foramen (fig. 6/13) on its medial aspect. The Os spleniale has the mylodyoid line (fig.6/12) on its medial aspect and the rostral mandibular fenstra (fig.5/10) on the lateral aspect. The $O s$ angular has only the medial process (fig.6/14).

Os hyoideum: The hyoid bone (fig.7) is situated within the framework of the mandible. It consists of three parts; axial unpaired elements (Os paraglossale (fig.7/2), Os basihyale (fig.7/3) and os urohyale (fig.7/4)) and the two paired elements; $O s$ ceratobranchiale (fig.7/6) and os epibranchiale (fig.7/7).

\section{Columna vertebralis (Vertebral column):}

Vertebrae cervicalis: The cervical vertebrae give the characteristic S-shape of the neck. They consist of 14 vertebrae. The cervical vertebrae are divided into two series; the cranial series (from $1^{\text {st }}$ to $6^{\text {th }}$ vertebra) and the caudal series (from 7th to 14th). The first cervical vertebra (Atlas) is a small, narrow ring-like (fig. 8\&9/1). The second cervical vertebra (Axis) (fig. $8 \& 9 / 2)$ short and has long triangular spinous process and no transverse process.

The bodies in the cranial series of the cervical vertebrae have ventral processes in the form of median and ventral crests except the first. The caudal series (from $7^{\text {th }}$ to $14^{\text {th }}$ cervical vertebrae) characterized by the presence of carotid processes (process caroticus) which are fused paired processes on the cranial part of the ventral surface of their bodies forming the cervical carotid canal (fig.8/4). The costal process (process costalis) (fig.8/3) is attenuated spine, directed caudally on the ventral aspect of the cranial series of cervical vertebrae. Transverse foramen (foramen transversarium) is found in all cervical vertebrae except atlas and axis.

Vertebrae thoracicae: The thoracic vertebrae are ten in number; all thoracic vertebrae (fig.10) are free (no Notarum). The last one fused with the synsacrum. The spinous processes (fig. 10/2) of the thoracic vertebrae are large, plate like processes projecting from the vertebral arch dorsally with the same height, except the first two are smaller. The transverse process (fig.10/3) of the thoracic vertebrae is broad and plate like projecting from the lateral aspect of the vertebral arch, except the first two are smaller.

Synsacrum: The synsacrum (fig. $11 / 8 \& 12 / 15$ ) is a fused bony rod of 12-13 lumbar and sacral vertebrae which are fused cranially with the tenth thoracic vertebra. The preacetabular series of synsacrum (fig.11/3) are the vertebrae which have connection with the preacetabular part of ilium (fig.11, 12\&13/2) through their fused spinous processes (crista spinosa synsacri, fig.11/4) and their transverse processes. The rest of the vertebrae of synsacrum don't have spinous processes but they have continuous fused transverse processes forming the lamina transversa synsacri (fig.11/5). The latter is connected laterally to the postacetabular part of ilium (fig.11/6) and has dorsally several foramina (foramina intertransversaria, fig.11/7) between the fused transverse processes.

Vertebrae caudales: The caudal vertebrae (Coccygeal vertebrae) (fig.11/11 \& 12/12) consist of five free coccygeal vertebrae and the pygostyle. The pygostyle (fig.11, 12\&13/10) is a sickle-shaped bony plate resulting from the fusion of the terminal (5-6) caudal vertebrae.

Costae (Ribs) (fig.10/4): there are seven pairs of ribs. These ribs include floating and true ones. The floating ribs (fig. 14/1) are the first and second ribs which have only vertebral parts and are free ventrally. The true ribs including $3^{\text {rd }}$ to $7^{\text {th }}$ ribs and each one has both vertebral (fig.14/4) and sternal (fig.14/5) parts; the vertebral parts articulate dorsally with the thoracic vertebrae while the sternal parts articulate distally with the sternum except the distal end of the seventh rib doesn't articulate directly with the sternum but with the sternal part of the sixth rib. Uncinate processes (fig. 14/3) are flat short processes which are directed caudodorsally from the caudal borders of all ribs except the last two ribs and the process of the first rib is very short. Each process lies against the cranial border of the next rib.

Sternum (breast bone, keel bone, fig. 15) is a large bony plate which is concave dorsally and convex ventrally. It has three surfaces; two external muscular surfaces and an internal visceral one. Carina sterni (crista sterni, fig.15/1) is the elongated triangular vertical plate from the ventral convex border, the cranial end of this crest is sharp concave and do not reach the craniodorsal end of sternum. Rostrum sterni (manubrium sterni) or (spina sterni, fig.15/2) is a median vertical bony plate at the craniodorsal end of sternum between the distal ends of coracoid bones.

Thoracic process (process thoracicus, fig.15/3) is a triangular process directed craniodorsally and lies on the caudal aspect of the coracoids. The caudolateral process (fig.15/4) is short and narrow bony process, it lies in the caudal part of the sternum. 

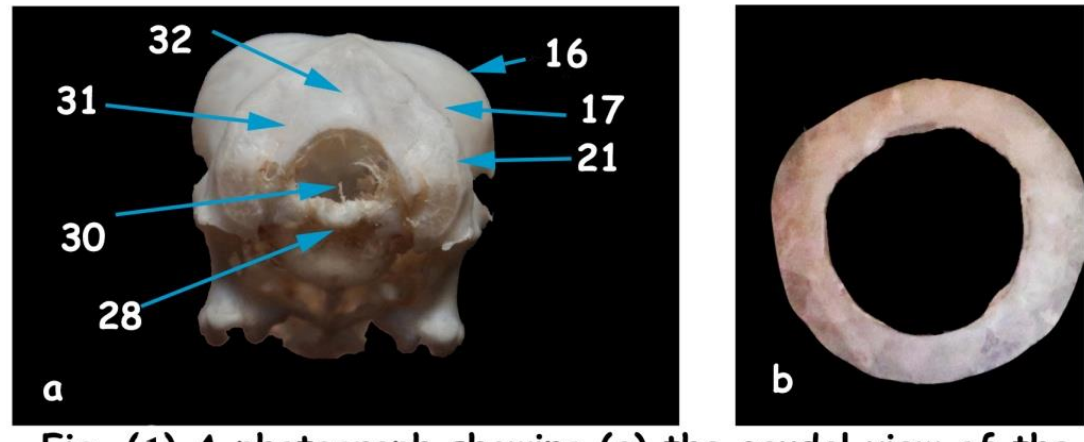

Fig. (1) A photograph showing (a) the caudal view of the Cranium (b) sclerotic ring

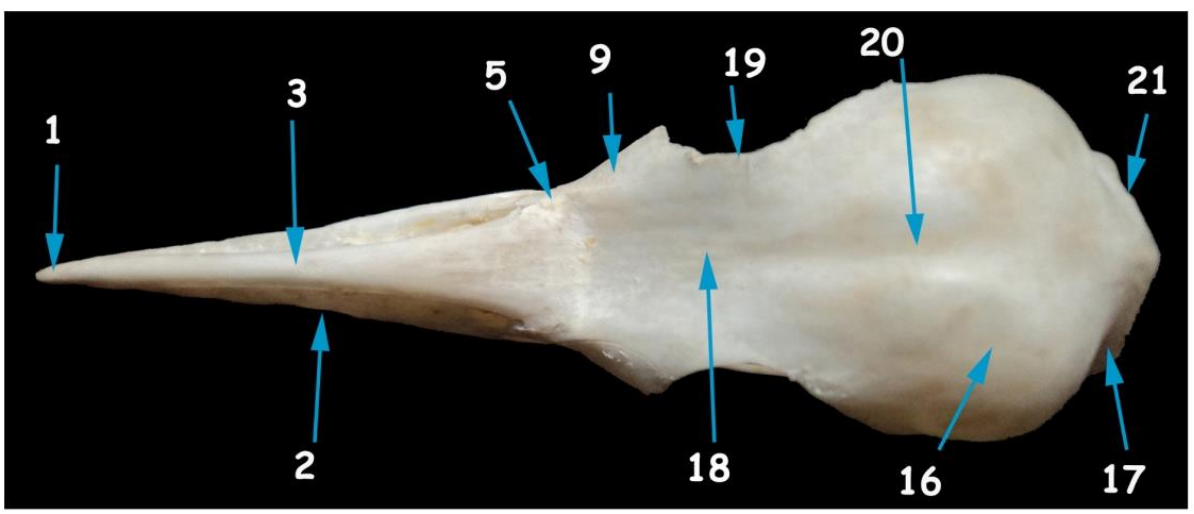

Fig. (2) A photograph showing the dorsal view of the Cranium

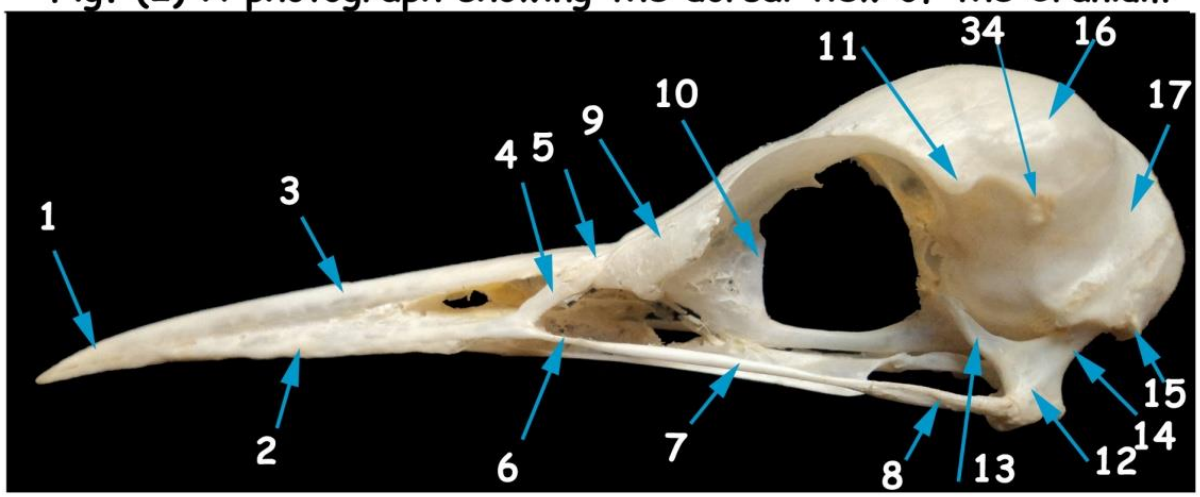

Fig. (3) A photograph showing the lateral view of the Cranium

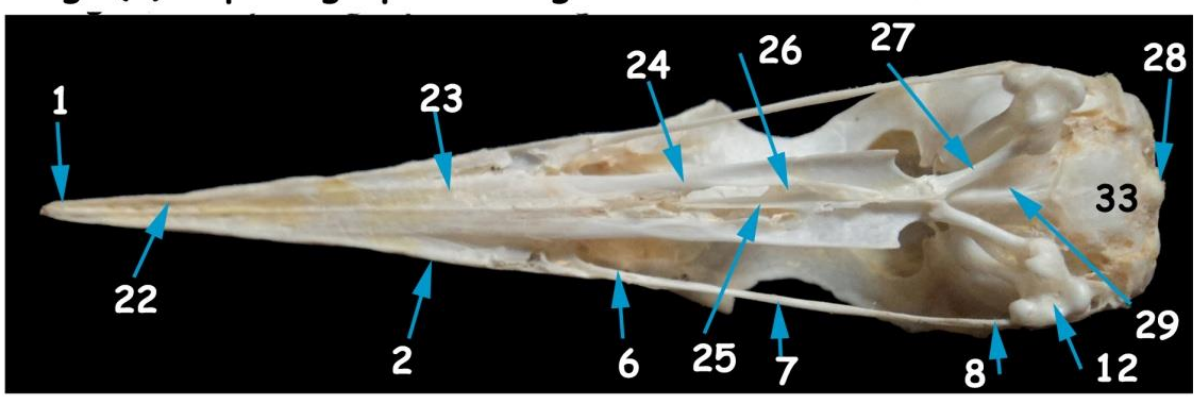

Fig. (4) A photograph showing the ventral view of the Cranium 


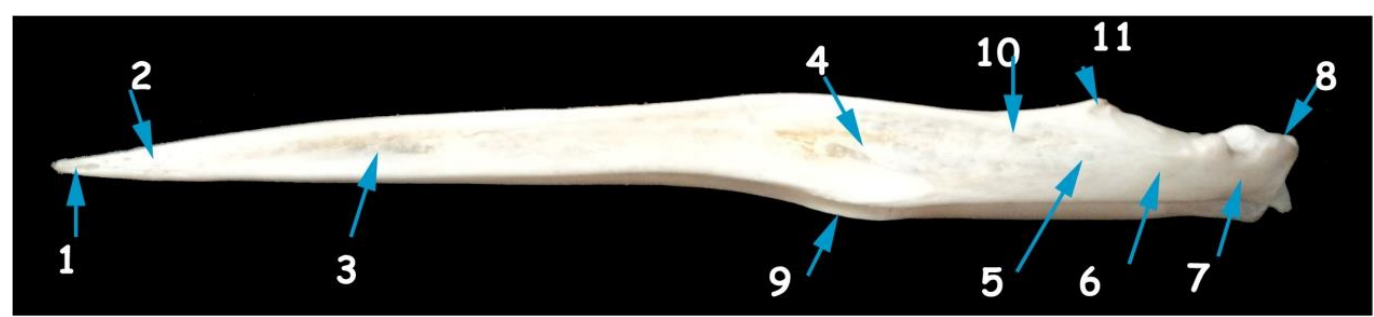

Fig. (5) A photograph showing the lateral view of the mandible

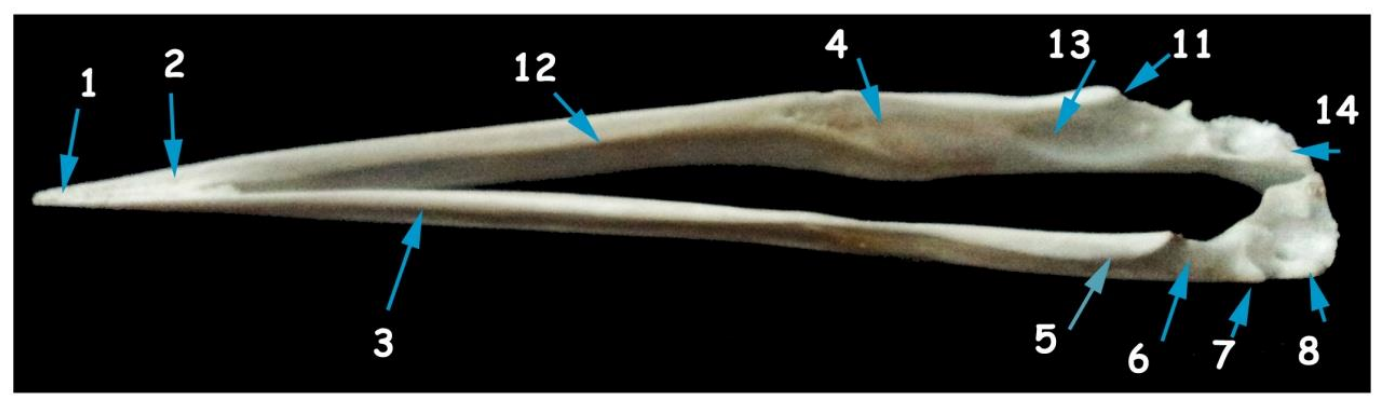

Fig. (6) A photograph showing the dorsomedial view of the mandible

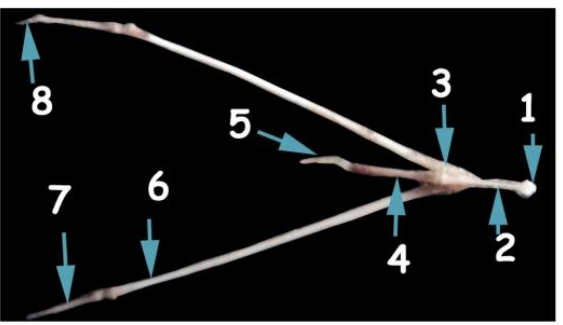

Fig. (7) A photograph showing the dorsal view of the hyoid bone

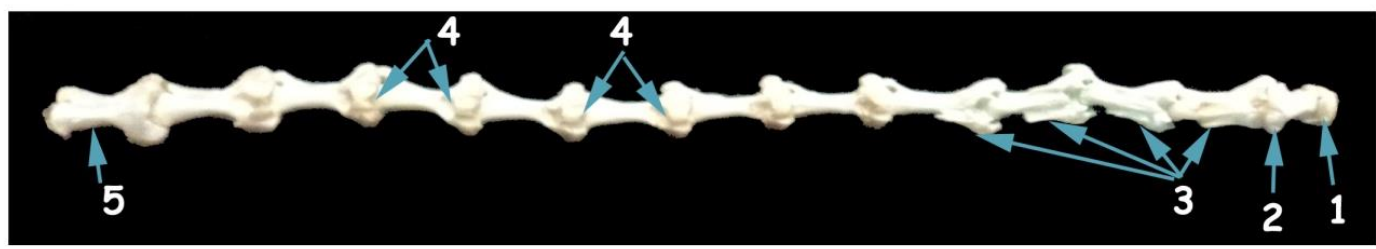

Fig. (8) A photograph showing the ventral view of the cervical vertebrae

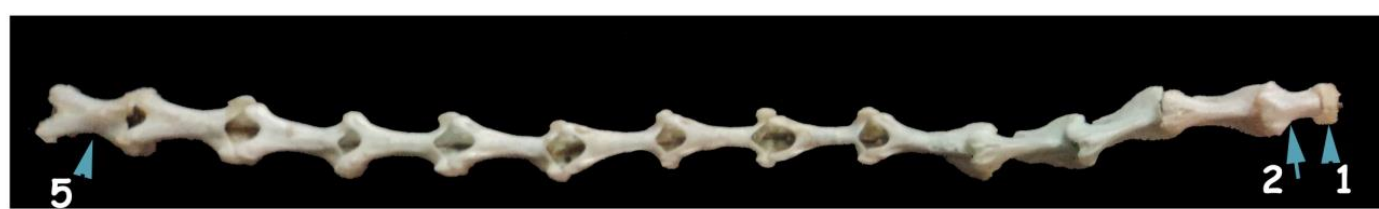

Fig. (9) A photograph showing the dorsal view of the cervical vertebrae 


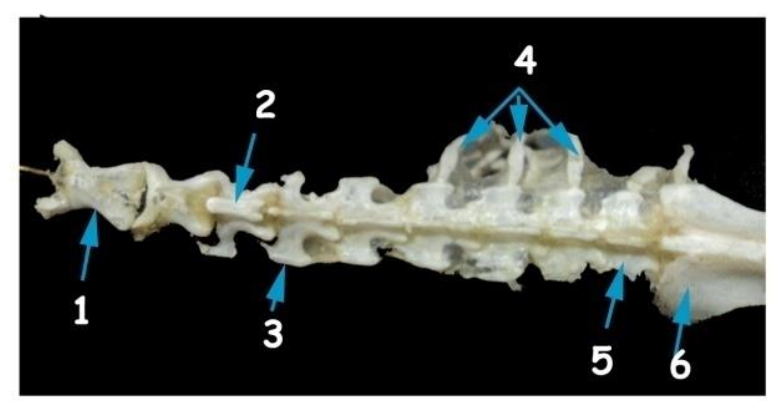

Fig. (10) A photograph showing the dorsal view of the thoracic vertebrae

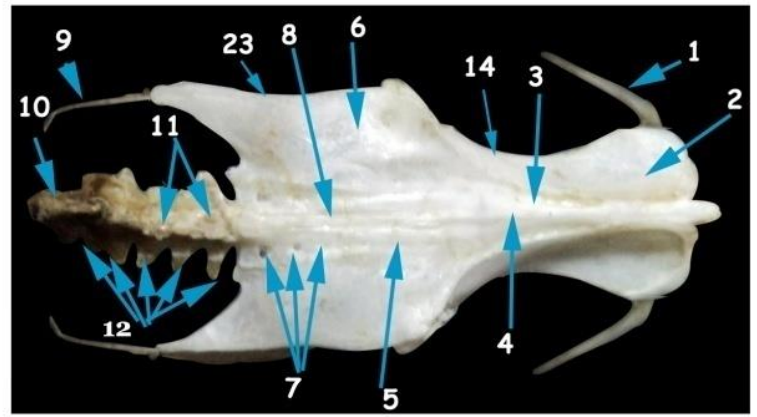

Fig. (11) A photograph showing the dorsal view of the synsacrum

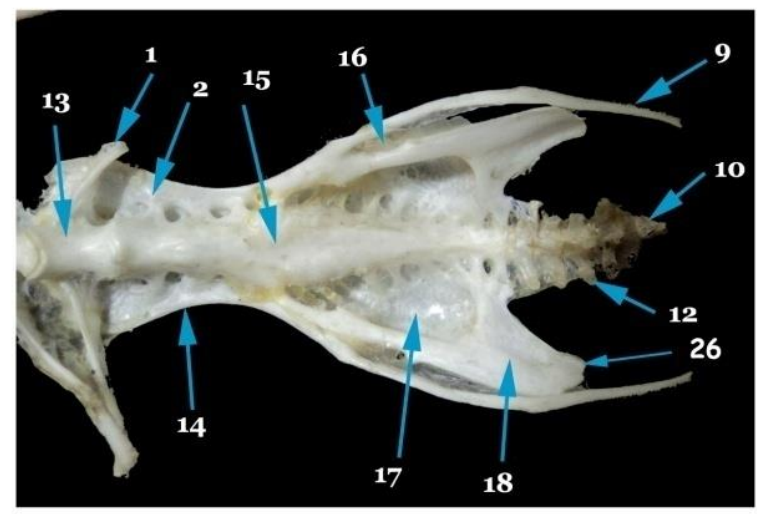

Fig. (12) A photograph showing the ventral view of the synsacrum

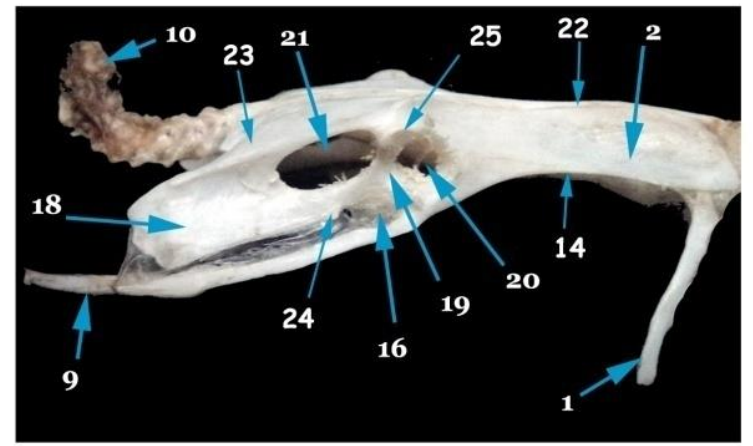

Fig. (13) A photograph showing the lateral view of the synsacrum 


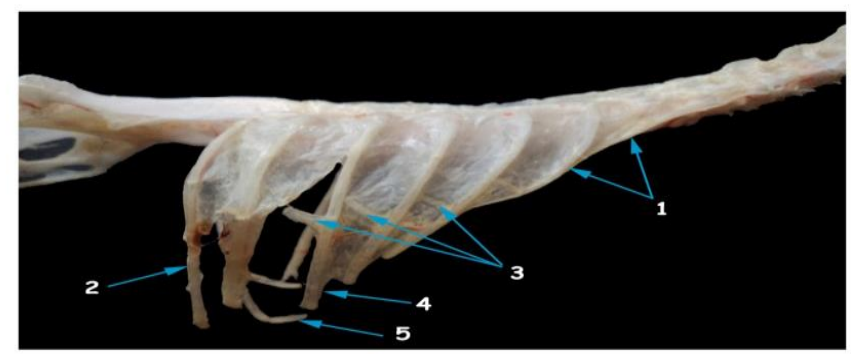

Fig. (14) A photograph showing the lateral view of the ribs

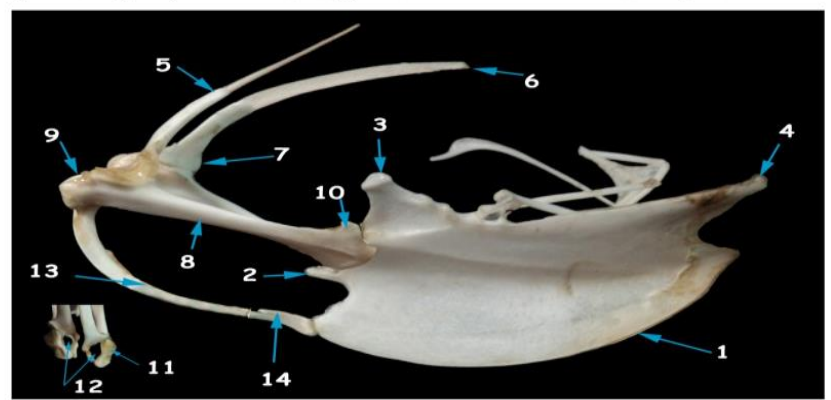

Fig. (15) A photograph showing the lateral view of the sternum, scapula, clavicle and coracoid

\section{Legend of figures (1-4):}

1-Os premaxillaris, 2-Os maxillare, 3- Facies dorsalis Os frontale, 4-Proc. maxillaries Os nasale, 5-Proc. frontalis Os nasale, 6-Proc. Jugalis Os maxillare, 7Os jugale, 8-Os quadratojugale, 9-Os lacrimale, 10Os mesoethmidale, 11-Proc. Postorbitalis Os temporalis, 12-Os quadratum13-Proc. Orbitalis Os quadratum, 14-Proc. oticus Os quadratum, 15-Proc. paroccipitalis, 16-Facies cerebralis Os frontale, 17-Os parietalis, 18-Facies orbitalis Os frontale, 19-Margo supraorbitalis, 20-Sulcus sinus sagittalis dorsalis, 21Crista nuchalis transversa, 22-Proc. palatines Os premaxillare, 23-Proc. maxillopalatinus, 24-Os palatinum, 25-Vomer, 26-Choana, 27-Os ptergoidium, 28-Condylus occipitalis, 29-Os basisphenoidale, 30-Foramen magnum, 31-Os exoccipitale, 32-Os supraoccipitale, 33-Os basioccipitale, 34-Proc. zygomaticus Os temporalis.

\section{Legend of figures (5 and 6):}

1-Rostrum mandibulae, 2-Os mentomandibulare, 3Os dentale, 4-Os spleniale, 5-Os supra-angulare, 6-Os prearticulare, 7-Os articulare, 8-Os angular, 9-
Angulus mandibulae, 10-Fenestra rostralis mandibulae, 11-Proc. coronoideus, 12- Linea mylodyoideus, 13-Foramen mandibulae, 14-Proc. medialis mandibulae.

\section{Legend of figures (7):}

1-Cornua paraglossum, 2- Paraglossum, 3-Basihyale, 4-Urohyale, 5-Cornu branchiale, 6-Ceratobranchiale 7-Epibranchiale, 8-Cornu epibranchiale.

\section{Legend of figures $(8 \& 9)$ :}

1-Atlas, 2-Axis, 3-Proc. costalis, 4-Canalis caroticus, 5-Fourteenth cervical vertebra.

\section{Legend of figures (10):}

1-First thoracic vertebra, 2-Proc. spinosa, 3-Proc. transversalis, 4-Costae, 5- $9^{\text {th }}$ thoracic vertebra, 6Ilium.

\section{Legend of figures (11-13):}

1-Seventh rib, 2-Pars preacetabularis ilii, 3-Extremtas cranialis synsaci, 4-Crista spinosa synsacri, 5-Lamina transversi synsacri, 6-Pars postacetabularis ilii, 7- 
Foramina intertransversi, 8-Synsacrum, 9-Pubis, 10Pygostylus, 11-Proc. Spinosa, 12-Proc. transverses, 13-Tenth thoracic vertebra, 14-Crista iliaca lateralis, 15-Corpus synsacri, 16-Foramen obturatum, 17-Fossa renalis, 18-Ischium, 19-Acetabulum, 20-Foramen acetabuli, 21-Foramen Ilioschiadicum, 22-Crista iliaca dorsalis, 23-Crista dorsolateralis ilii, 24-Proc. obturatorius, 25-Antitrochanter, 26-Proc. terminalis ischii.

\section{Legend of figures (14):}

1-Floating ribs, 2-Seventh rib, 3-Proc. uncinatus, 4Costa vertebralis, 5-Costa sternalis.

\section{Legend of figures (15):}

1-Carina sterni, 2-Manubrium sterni, 3-Process thoracicus, 4-Proc. caudolateralis sterni, 5-Scapula, 6Extremitas caudalis scapulae, 7-Extremitas cranialis scapulae, 8-Coracoideum, 9-Extremitas omalis coracoidei, 10-Extremitas sternalis coracoidei, 11Facies articularis humeralis, 12-Canalis triosseus, 13Clavicula, 14-Hypocleideum.

\section{DISCUSSION}

In the present study the occipital bone of skull composed of four fused components with single occipital condyle. These findings agreed with that stated by Nickel et al. (1977), Baumel et al. (1993), Dyce et al. (2002) in domestic birds and Tahon et al. (2013) in chicken.

The present study as well as those of Baumel et al. (1993) and Tahon et al. (2013) in chicken revealed that the supraoccipital bone has Transverse nuchal crest separating the nuchal plane of the supraoccipital bone from the parietal and temporal bones rostrally.

Each Frontal bone was consisting of the fused frontal, orbital and nasal parts, these results were in agreement with Nickel et al. (1977) and Tahon et al. (2013) in chicken.

In accordance with Nickel et al. (1977) and Tahon et al. (2013) in chicken, the temporal bone consisted of two parts; the Os oticum (ear capsule) and squamous part.

In agreement with the description of Baumel et al. (1993) and Tahon et al. (2013) in chicken, the Paroccipital process (Ala posttympanica) forms the caudal wall of the tympanic cavity and the acoustic meatus, while Zusi (1962) in black skimmer named it as the opisthoticus process, a condition which disagreed with our observation. Also, Richards and Bock (1973) in Loxops and Johnson (1984) in Europian oystercatcher added that its name was the exoccipital process.
Ethmoid bone consists of Os mesethmoidale and $O s$ ectethmoidale, these findings were simulated the observations of Baumel et al. (1993) and Tahon et al. (2013) in chicken.

The nasal bone was formed of two processes; frontal and maxillary processes. This result was disagreed with that of Nickel et al. (1977), Dyce et al. (2002) in domestic birds and Tahon et al. (2013) in chicken; they reported that there is a third process of the nasal bone named premaxillary process.

The frontal, maxillary and palatine processes of the premaxillary bone were recorded by Nickel et al. (1977) in domestic birds and Tahon et al. (2013) in chicken.

The present study as well as that of Baumel et al (1993) and Tahon et al. (2013) in chicken revealed that the jugal bones (zygomatic bones) consisted of three fused bones. Also, the vomer bone is a single, median, laterally compressed plate.

In agreement with the description of Nickel et al. (1977), Baumel et al. (1993) and Tahon et al. (2013) in chicken, the quadrate bone has three processes; otic, orbital and mandibular.

The present study as well as those of Baumel et al. (1993) and Tahon et al. (2013) in chicken revealed that the mandible is formed of seven bones fused with each others. However, Hogg (1983) in domestic fowl described that only six elements present in the mandible.

Os supra-angulare of mandible has on its dorsal border the coronoid process while, Johnson (1984) named it as angulus mandibulae; this result is disagreed with Zweers (1974) who revealed that the coronoid process is located on the lateral surface of the mandible. The mandibular foramen of the Os supra-angulare was named as fossa medialis mandibulae by Johnson (1984).

The present study and those of Homberger and Meyers (1989) as well as Tahon et al. (2013) in chicken revealed that the hyoid bone consists of three parts, axial unpaired elements and two paired elements.

The cervical vertebrae in cattle egret were recorded as 14 in number simulating what stated by Avila (1995), Gietema (2005) and Egwu et al. (2012) and Tahon et al. (2013) in chicken. On the other hand, Dyce et al. (2002) and Hathaway and Buckley (2004) mentioned that in chicken the cervical vertebrae ranged between 14-17. 
The carotid sulcus mentioned by Tahon et al. (2013) in chicken was not found in this study, as the carotid processes are long enough to fused forming carotid canal.

The number and fusion of the thoracic vertebrae were matter of controversy among different authors. In this aspect, the present work recorded ten thoracic vertebrae in cattle egret, all are free except the last vertebra is fused with the synsacrum. In chicken Tahon et al. (2013) mentioned that, the $1^{\text {st }}$ and $6^{\text {th }}$ thoracic vertebrae are free from the $2^{\text {nd }}$ to the $5^{\text {th }}$ fused together forming the notarium, while the last $\left(7^{\text {th }}\right)$ vertebra is fused with the synsacrum, However, Hogg (1982), Mclelland (1990) and Akers and Denbow (2008) stated that the last cervical and first three thoracic vertebrae are fused in the thoracic region to form notarium.

Synsacrum is a fused bony rod of 12-13 lumbar and sacral vertebrae which are fused cranially with the tenth thoracic vertebra, However, Hogg (1982) recorded that the lumbosacral region (synsacrum) in chicken is composed of 14-16 elements and the last fifth thoracic vertebra in all birds was involved in synsacrum.

In agreement with Nickel et al. (1977) and Tahon et al. (2013) in chicken the free caudal (coccygeal) vertebrae are five in number, However, Akers and Denbow (2008) revealed that there are six free caudal vertebrae in chicken.

In agreement with the observations of Nickel et al. (1977) and Tahon et al. (2013) in domestic fowl and Tickle and Codd (2009) in turkey, that the ribs of cattle egret are seven pairs. On the other hand Mclelland (1990) and Dyce (2002) found that in chicken there are (5-6) pairs of ribs.

The present investigation declared the presence of uncinate processes in all ribs except the last two ribs and that of the $1^{\text {st }}$ rib is very short. In this respect, Nickel et al. (1977) and Tahon et al. (2013) in chicken recorded that the first and last two ribs are devoid of such uncinate processes.

\section{REFERENCES}

Abou Shafey, H.E. (2012): Desportesius invaginatus (Linstow, 1901) Chabaud and E. Campana, 1949 (Nematoda, Acuariidae) from Ardeola ibis ibis with Reference to the Fine Structure of the Cordons. PUJ; 2012, 5(1): 49-57.

Akers, R.M. and Denbow, D.M. (2008): Anatomy and physiology of domestic animals, Blackwell publishing.

Avila, V. (1995): Investigating life on earth. Jones and Bartlett publishers, USA: 1995. pp. 801-803.
Baumel, J.J.; King, A.S.; Breazile, J.E.; Evans, H.E. and Vanden Berge, J.C. (1993): Nomina Anatomica Avium. Handbook of avian anatomy ( $2^{\text {nd }}$ edition) Chapter:4. pp. 45-132.

Dyce, K.M.; Sack, W.O. and Wensing, C.J.G. (2002): Text book of Veterinary Anatomy, $3^{\text {rd }}$ edition, p.p. 815-819. Saunders Company, Philadelphia, London, New York, ST. Louis, Sydney, Toronto.

Egwu, O.A.; Ukoha, U.U.; Okafor, J.I. and Chukwudebelu, T.G. (2012): The Skeleton of Domestic Fowl (Gallus domesticus): a Comparative Morphologic Study. World J. Life Sci. and Medical Research 2012; 2:39.

Gietema, B. (2005): The basics of chicken farming (in the topics). $1^{\text {st }}$ ed. ISBN:905285 006.

Hathaway, L. and Buckley, (2004): Analysis of the anatomy and physiology of the chicken in comparison to the human. Block 2 anatomy/ physiology honors, November 19.

Hogg, D.A. (1982): Fusions occurring in the post cranial skeleton of the domestic fowl. J. Anat. 135 (3): 501-512.

Hogg, D.A. (1983): Fusions within the mandible of the domestic fowl (Gallus gallus domesticus). J. Anat. (1983), 136, 3, pp. 535-541.

Homberger, D.G. and Meyers, R.A. (1989): Morphology of the lingual apparatus of the domestic chicken, Gallus gallus, with special attention to the structure of the fasciae. The anatomical journal of anatomy 186: 217-257 (1989).

Johnson, R. (1984): The cranial and cervical osteology of the European Oystercatcher Haematopusostralegus. J. Morph. 182: 227-244.

Mclelland, J. (1990): A color Atlas of Avian Anatomy. Wolfe Publishing LTD. pp. 33-46.

Nickel, R.; Schummer, A. and Seiferle, E. (1977): Anatomy of domestic birds. pp. 5-25. ISBN 3489-55418-3 Verlag Paul Parey, Berlin and Hamburg.

Richards, L.P. and Bock, W.J. (1973): Functional anatomy and adaptive evolution of the feeding apparatus in the Hawaiian Honeycreeper genus Loxops (Drepanididae). Amer. Ornith. Union, Ornith. Monogr., no. 15, 173 pp.

Sullivan, L.M. and Romney, C.P. (1999): Cleaning and Preserving Animal Skulls. The university of Arizona cooperative extension, collage of Agriculture, Tucson, Arizona 85721.Ag. Arizona. Edu/pubs/natresources/a21144.pdf.

Tahon, R.R.; Ragab, S.A.; Abdel Hamid, M.A. and Rezk, H.M. (2013): Some anatomical studies on the skeleton of chickens. Ph.D. Thesis. Anatomy and Embryology, Faculty of Veterinary Medicine, Cairo University.

Tickle, P.G. and Codd, J.R. (2009): Ontogenic development of the uncinate processes in the 
domestic turkey (Meleagris gallopavo). Poultry science 88: 179-184.

Zusi, R.L. (1962): Structural Adaptations of the Head and Neck in the Black Skimmer, Rynchopsnigra. Publ. Nuttall Ornith. Club, no. 3 , viii + .101 pp.
Zweers, G.A. (1974): Structure, movement, and myography of the feeding apparatus of the mallard (Anas platyrhynchos). A study in functional anatomy. Neth. J. Zool., 24: 323-467.

\title{
فحص تشريحي للهيكل العظمي المحوري في طائر أبو قردان
}

\author{
حمدى رنق \\ Email: hamdyrezk81@cu.edu.eg Assiut University Email: www.aun.edu.eg
}

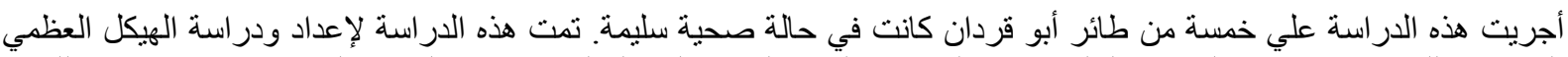

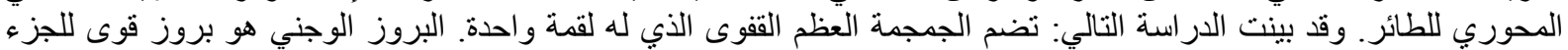

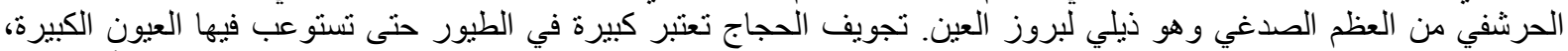

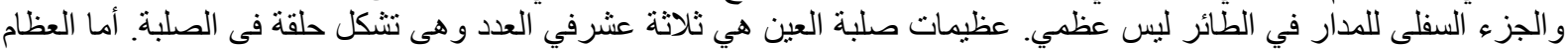

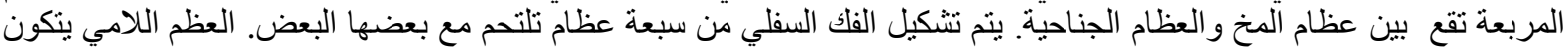



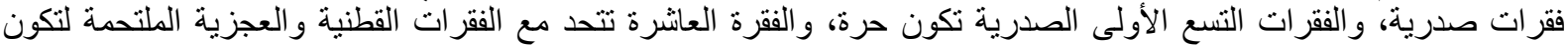

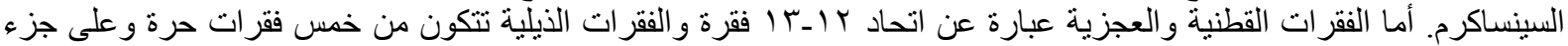

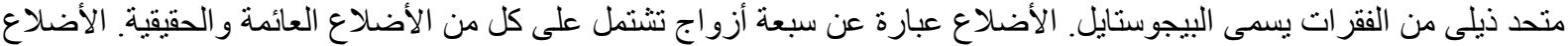

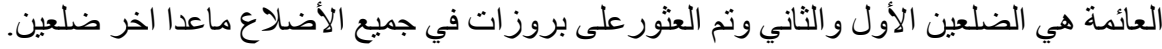

